\title{
Systemic risk factors contribute differently to the development of proliferative diabetic retinopathy and clinically significant macular oedema
}

\author{
Toke Bek ${ }^{1}$ \\ Received: 13 February 2020 / Accepted: 3 June 2020 / Published online: 21 July 2020 \\ (C) Springer-Verlag GmbH Germany, part of Springer Nature 2020
}

\begin{abstract}
Aims/hypothesis The purpose of screening for diabetic retinopathy is to detect either of the two sight-threatening complications: proliferative diabetic retinopathy (PDR) or clinically significant diabetic macular oedema (DME). The aim of the study was to evaluate whether systemic risk factors affect the risk of developing these two complications differently.

Methods Survival analysis with death as a competing risk was used to describe the effect of sex, age and time of onset of diabetes, systolic (SBP) and diastolic (DBP) BPs, and the weighted exposure and CV of HbA $1 \mathrm{c}$ for the development of PDR and DME from all 2773 patients treated for diabetic retinopathy in a defined population from the Aarhus area, Denmark, between 1 July 1994 and 1 July 2019.

Results Increasing $\mathrm{HbA}_{1 \mathrm{c}}$ above normal increased the risk of developing both PDR and DME $(p<0.04)$, and values below normal increased the risk of developing PDR $(p<0.013)$. Increasing DBP increased the risk of developing both PDR and DME $(p<0.0001)$, whereas increasing SBP increased the risk of developing DME $(p<0.0001)$, but not PDR $(p>0.08)$. The risk of developing PDR increased with decreasing age of onset of diabetes $(p<0.0001)$, whereas the risk of developing DME was maximal for a known onset of diabetes at about 30 years of age and decreased significantly for both lower and higher ages of onset $(p<0.0001)$. The risk of developing both PDR and DME was lower in women than in men $(p<0.004)$ and was reduced with lower variability of repeated $\mathrm{HbA}_{1 \mathrm{c}}$ measurements $(p<0.0001)$.

Conclusions/interpretation Systemic risk factors such as metabolic regulation, arterial BP and the age of onset of diabetes contribute differently to the development of PDR and DME. The overall risk of developing treatment-requiring diabetic retinopathy should be calculated from the risks of reaching each of the two complications separately.
\end{abstract}

Keywords Age of onset of diabetes $\cdot$ Blood pressure $\cdot$ Diabetic macular oedema $\cdot$ Metabolic regulation $\cdot$ Proliferative diabetic retinopathy $\cdot$ Risk factors $\cdot$ Survival analysis

\section{Abbreviations}

DBP Diastolic BP

DME Diabetic macular oedema

PDR Proliferative diabetic retinopathy

SBP Systolic BP

VEGF Vascular endothelial growth factor

${ }_{\text {wHbA }}$ Weighted $\mathrm{HbA}_{1 \mathrm{c}}$

Toke Bek

toke.bek@mail.tele.dk

1 Department of Ophthalmology, Aarhus University Hospital, DK-8200 Aarhus N, Denmark

\section{Introduction}

The aim of screening for diabetic retinopathy is to detect either of the two sight-threatening complications: proliferative diabetic retinopathy (PDR) and diabetic maculopathy with clinically significant macular oedema (DME) [1]. The development of PDR is related to capillary occlusion in the retinal periphery, and DME to vascular hyperpermeability in the macular area, which implies that the two complications can occur both separately and together [2, 3]. The progression of diabetic retinopathy is described on a semi-quantitative scale ranging from no retinopathy to PDR, with the presence, or not, of DME added to this scale. This principle was introduced in the late 1960s [4], when PDR in type 1 diabetic individuals was the predominant type of sight-threatening retinopathy, 


\section{Research in context}

\section{What is already known about this subject?}

- Systemic risk factors such as sex, metabolic regulation, arterial BP and age of onset of diabetes are known to affect the risk of developing sight-threatening diabetic retinopathy

\section{What is the key question?}

- Do these systemic risk factors contribute differently to the development of proliferative diabetic retinopathy (PDR) and diabetic macular oedema (DME)?

\section{What are the new findings?}

- Age of diabetes onset, metabolic regulation and arterial BP contribute differently to the development of PDR and DME

- Lower than normal $\mathrm{HbA}_{1 \mathrm{c}}$ increases the risk of developing sight-threatening diabetic retinopathy

- The overall risk of developing treatment-requiring diabetic retinopathy should be assessed from the risks of reaching the two complications PDR and DME separately

How might this impact on clinical practice in the foreseeable future?

- The findings may be used to improve algorithms for calculating optimal intervals between screening examinations for diabetic retinopathy

and has been extended to current adaptations of the scale [5, 6]. During recent decades, the increasing incidence of type 2 diabetes has resulted in an increase in the incidence of DME to become a separate endpoint that should be detected and treated $[7,8]$. Therefore, it is possible that systemic risk factors such as sex, BP, metabolic regulation and the variables underlying the definition of diabetes type [9] may also affect the risk of developing the two treatment endpoints differently. Studies of how risk factors affect diabetic retinopathy endpoints should consider that such effects may not be monotonic, and, since long follow-up times are required, the data should be corrected for the death of the population over time.

Survival analysis with death as competing risk was therefore used to describe individual systemic risk factors for the development of PDR and DME from all 2773 patients treated for diabetic retinopathy in a defined population from the Aarhus area, Denmark, between 1 July 1994 and 1 July 2019.

\section{Methods}

Patients The study was performed using data in the diabetic retinopathy database at the Department of Ophthalmology, Aarhus University Hospital, which by 1 July 2019 contained prospectively collected clinical data and gradings of fundus photographs from 80,198 examinations performed in 18,252 diabetic individuals since 1 December 1992. The data include all patients treated for diabetic retinopathy from a well-defined population of approximately 650,000 citizens (from 1 January 1992 to 31 December 2006), which was subsequently extended to approximately 900,000 citizens as part of an administrative reform of the Danish healthcare system [10]. Diabetic individuals were followed according to national diabetic retinopathy screening guidelines. This meant that those with type 1 diabetes, and those with type 2 diabetes where the general practitioner requested specialised endocrinological monitoring, were screened in a secondary care facility in the ophthalmology department. Otherwise, individuals were screened by private practice ophthalmologists.

The department's routine examination programme has been described previously [11-13] and includes interviewing patients about the age of onset and the type of pharmacological treatment of diabetes, measurement of best-corrected visual acuity and BP (from 1 December 1999). $\mathrm{HbA}_{1 \mathrm{c}}$ values were collected from the regional laboratory database (from 1 January 1992), except for those of individuals with known haemolytic disease, dehydration or other conditions known to affect the measurement. Information about deaths was obtained from the national death register and all data were entered prospectively into a structured patient record that allowed the extraction of data for quality assessment.

The following patients in the database were excluded from the study: 23 with questionable diabetes, 69 with gestational diabetes, 51 with diabetes secondary to pancreatic disease or steroid medication and 28 with known hereditary diabetes. Among the remaining 18,081 patients, 477 were being followed outside the region for a part of the diabetes duration, and 98 had an unknown time of onset of diabetes, which resulted in the inclusion of 17,506 patients in the study: 10,051 men and 7455 women. Type 1 diabetes had been registered in 4510 patients who had insulin-requiring diabetes with onset before the age of 30 years, or diabetes with onset between the ages of 
30 and 40 years in whom insulin treatment was required within the first year of onset. The remaining 12,996 patients had been registered with type 2 diabetes. The included patients had been examined a total of 78,771 times and had been followed for $5.53 \pm 6.92$ years $($ mean $\pm S D$, range 0 27.1 years); during the period, $6466(36.9 \%)$ patients had died.

Treatment All patients were referred to the ophthalmology department for specialist evaluation if a sight-threatening complication was suspected; when a complication was verified by a retina specialist, treatment was carried out in the department. During the 25 year period from 1 July 1994 to 1 July 2019, 2773 patients had been diagnosed with and treated for sight-threatening retinopathy for the first time in the first eye. Among these, 1164 had first been treated for PDR, defined as pre-retinal neovascularisations emerging from the larger vascular arcades or the optic disk [13]. The treatment consisted of pan-retinal photocoagulation delivered in a grid pattern spread over at least three sessions, as described previously [14], which from 1 January 2018 was preceded by intravitreal injection of anti-vascular endothelial growth factor (VEGF) compound. The remaining 1609 patients had first been treated for diabetic maculopathy with clinically significant DME [15]. In those patients, photocoagulation was applied in a grid pattern corresponding to the area with retinopathy lesions but sparing the papillomacular bundle and a zone of approximately $400 \mu \mathrm{m}$ around the fovea [16]. After 1 January 2017, patients with centre-involving DME were treated with intravitreal injection of anti-VEGF medication [10]. All treatments were initiated in the eye with the most severe retinopathy; in patients whose retinopathy was considered to be of the same severity in the two eyes, treatment was started in the right eye. Therefore, treatment was started in 1640 right eyes and 1133 left eyes; 2573/2773 (93\%) of these treatments were performed by the author. There was no significant difference between the diabetes durations at the time of treatment of patients in the 25 individual years from which treatment data were collected (one-way ANOVA, $p>0.14$ ).

Time-to-event The time-to-event was defined as the time from the known onset of diabetes until the date between 1 July 1994 and 1 July 2019 when the patient received the first treatment in the first eye for diabetic retinopathy, either for PDR (panretinal photocoagulation, vitrectomy, treatment of neovascular glaucoma, or preparation for such procedures by intravitreal anti-VEGF injection) or for diabetic maculopathy with clinically significant DME (macular photocoagulation, intravitreal injection with anti-VEGF compound or steroid). In patients who had died without receiving treatment (competing risk), the event was set to the time of death, whereas the follow-up times of the remaining patients were censored at 1 July 2019.
Covariates Sex was included as a binary variable $(\operatorname{men}=1$, women $=0$ ). Continuous variables were the known time of onset of diabetes, in years, after 1 January 1960 (mean \pm SD, $37.2 \pm 12.46 ; n=17,506)$ and the known age of onset of diabetes (mean $\pm \mathrm{SD}, 45.3 \pm 20.1 ; n=17,506)$. $\mathrm{HbA}_{1 \mathrm{c}}$ values were used to calculate the weighted mean of this variable for each individual patient during the time-to-event (or censoring), which was expected to reflect the total exposure to the variable over time better than a single value. Values obtained before 1 January 2008 had been recorded in per cent (weight/weight) and were converted to $\mathrm{mmol} / \mathrm{mol}$ to become comparable with subsequently obtained values. A transition period of 3 months during which values had been obtained in both units ensured the validity of the conversion, and the normal value was set to $42 \mathrm{mmol} / \mathrm{mol}(6.0 \%)$. This resulted in altogether 482,105 $\mathrm{HbA}_{1 \mathrm{c}}$ values from 16,352 patients from 1 June 1992. The weighted $\mathrm{HbA}_{1 \mathrm{c}}\left(\mathrm{wHbA}_{1 \mathrm{c}}\right.$ ) was calculated as follows: the total time of observation for $\mathrm{HbA}_{1 \mathrm{c}}$ was defined to start 90 days before the first $\mathrm{HbA}_{1 \mathrm{c}}$ measurement and to last until the time of event (treatment, death or 1 July 2019). Subsequently, each $\mathrm{HbA}_{1 \mathrm{c}}$ value was weighted according to the time from the previous measurement, except for the first measurement, which was weighted from the beginning of the observation period, and the last measurement, where the time of the weight was extended to the end of the observation period. The $\mathrm{CV}$ of the recorded $\mathrm{HbA}_{1 \mathrm{c}}$ values was calculated from 15,870 patients where more than one $\mathrm{HbA}_{1 \mathrm{c}}$ value was available. On the basis of 42,301 BP measurements from 13,383 patients, the weighted DBP and SBP were calculated using the same procedure as used for calculating the $\mathrm{wHbA}_{1 \mathrm{c}}$. The background characteristics of patients with the two complications are shown in Table 1.

The study was approved by the regional ethics committee, the Danish Patient Safety Authority and the Danish Data Protection Agency (application no. 2015-57-0002).

Statistical analysis All analyses were performed in Stata, version 14.2 (StataCorp LP, USA), using survival analysis, with the development of either PDR or DME in the first eye as the event and with death as a competing risk, and so that competing events resulted in right censoring of data. Visual acuities were $\log _{10}$-transformed before the calculation of mean values and CIs, and these parameters were subsequently anti$\log _{10}$-transformed for presentation.

For the binary variable, sex, the dataset was stratified into the two outcomes, PDR and DME, and for each of the continuous variables the dataset was stratified into intervals, i.e. time of onset of diabetes between 1 January of the years: $(-\infty, 1998$ [, [1998,2003[, [2003, $\infty)$, known age at onset of diabetes (years): $[0,15[,[15,30[,[30,45[,[45,60[,[60, \infty)$, $\mathrm{wHbA}_{1 \mathrm{c}}(\mathrm{mmol} / \mathrm{mol}):([0,40[,[40,70[,[70,100[,[100, \infty)$, the square root of the CV of $\mathrm{wHbA}_{1 \mathrm{c}}$ : [0,3[, [3,5[, [5,7[, [7,9[, [9, $\infty)$ DBP (mmHg): [0,60[, [60,80[, [80,100[, [100, $\infty)$ SBP (mmHg): [0,120[, [120,140[, [140,160[, [160, $\infty)$. 
Table 1 Background characteristics at the time of treatment of patients with PDR and diabetic maculopathy with clinically significant DME

\begin{tabular}{|c|c|c|}
\hline Risk factors & PDR & DME \\
\hline \multicolumn{3}{|l|}{ Non-modifiable risk factors } \\
\hline Sex, male/female, ratio $(n)$ & $707 / 457,1.55(1164)$ & $967 / 642,1.51(1609)$ \\
\hline Diabetes type, type $1 /$ type 2 , ratio $(n)$ & $567 / 597,0.95(1164)$ & $249 / 1360,0.18(1609)$ \\
\hline Insulin medication, yes/no, ratio $(n)$ & $961 / 203,4.73(1164)$ & $1098 / 511,2.15(1609)$ \\
\hline Eye of first treatment, right/left, ratio $(n)$ & $671 / 493,1.36(1164)$ & $966 / 643,1.50(1609)$ \\
\hline Known age of onset of diabetes, in years, mean $\pm \mathrm{SD}(n)$ & $32.1 \pm 19.7(1.164)$ & $46.9 \pm 16.0(1609)$ \\
\hline Known diabetes duration at first treatment, in years, mean $\pm \mathrm{SD}(n)$ & $19.8 \pm 11.6(1164)$ & $14.1 \pm 9.7(1609)$ \\
\hline \multicolumn{3}{|l|}{ Modifiable risk factors } \\
\hline \multicolumn{3}{|l|}{$\mathrm{wHbA}_{1 \mathrm{c}}$, mean $\pm \mathrm{SD}(n)$} \\
\hline $\mathrm{mmol} / \mathrm{mol}$ & $77.0 \pm 19.3(839)$ & $71.0 \pm 17.4(1290)$ \\
\hline$\%$ & $9.2 \pm 3.9$ & $8.6 \pm 3.5$ \\
\hline $\mathrm{CV}$ of $\mathrm{HbA}_{1 \mathrm{c}}$, mean $\pm \mathrm{SD}(n)$ & $18.1 \pm 16.1(780)$ & $20.4 \pm 15.4(1245)$ \\
\hline wSBP in $\mathrm{mmHg}$, mean $\pm \mathrm{SD}(n)$ & $142.5 \pm 22.3(519)$ & $148.6 \pm 22.7(1149)$ \\
\hline $\mathrm{wDBP}$ in $\mathrm{mmHg}$, mean $\pm \mathrm{SD}(n)$ & $82.0 \pm 12.0(519)$ & $83.1 \pm 11.6(1149)$ \\
\hline \multicolumn{3}{|l|}{ Visual function } \\
\hline Visual acuity, mean $[95 \% \mathrm{CI}](n)$ & $0.50[0.47,0.53](1511)$ & $0.51[0.49,0.53](925)$ \\
\hline
\end{tabular}

wDBP, weighted DBP; wSBP, weighted SBP

For each variable, the Aalen-Johansen estimator applicable for survival data with competing risks was calculated to describe the cumulative incidence for each of the defined strata. The cumulative incidence described the percentage of patients who had acquired sight-threatening retinopathy among those who were alive at each diabetes duration. The model assumes that each patient is assigned to one of three alternatives of right censoring, i.e. death, alive with treatment endpoint or alive without treatment endpoint. As log-minus$\log$ plots indicated that the hazards among the different strata were not proportional, the influence of the different strata was compared using the pseudo-values method, which is a generalised linear model that should be computed for different survival rate times, performed here at 10,20,30 and 40 years [17].

For each variable it was noted whether each of the different strata contributed significantly to the variation of the variable,
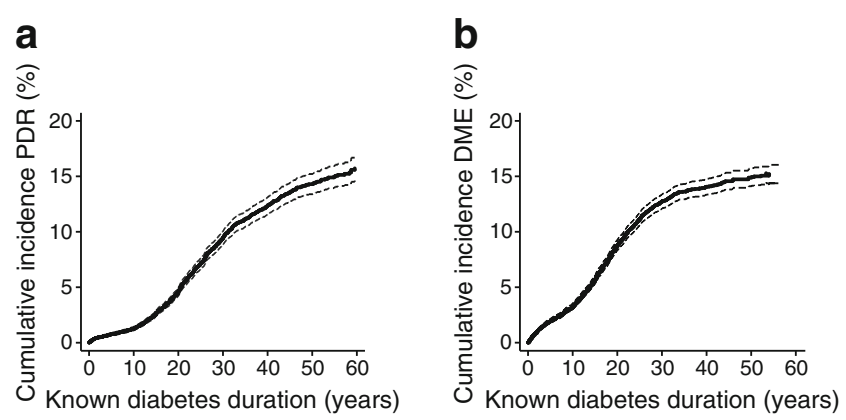

Fig. 1 Overall cumulative risk of developing (a) PDR and (b) DME, as a function of known diabetes duration $(n=17,506)$. The dashed lines delimit the $95 \%$ CIs and the $\chi^{2}$ test was used to test whether the contributions of the defined strata, together and pairwise, differed significantly.

\section{Results}

Figure 1 shows the overall cumulative incidence of first developing either PDR or diabetic maculopathy with clinically significant DME, as a function of diabetes duration in the studied population. It appears that for both complications the cumulative incidence was approximately $15 \%$ after 60 years

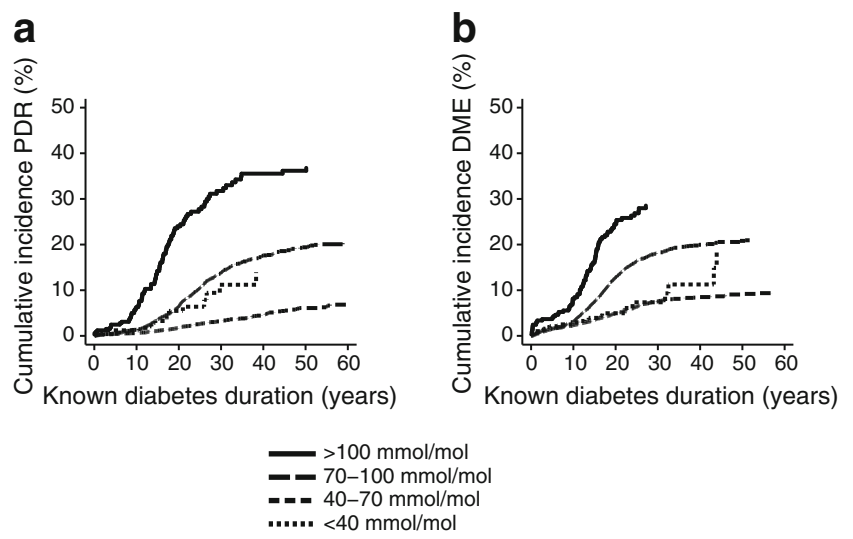

Fig. 2 Cumulative risk of developing (a) PDR and (b) DME, as a function of known diabetes duration, for patients stratified according to the weighted exposure to $\mathrm{HbA}_{1 \mathrm{c}}(>100 \mathrm{mmol} / \mathrm{mol}, n=328 ; 70$ $100 \mathrm{mmol} / \mathrm{mol}, n=3723 ; 40-70 \mathrm{mmol} / \mathrm{mol}, n=11,728 ;<40 \mathrm{mmol} /$ mol, $n=572$ ) 

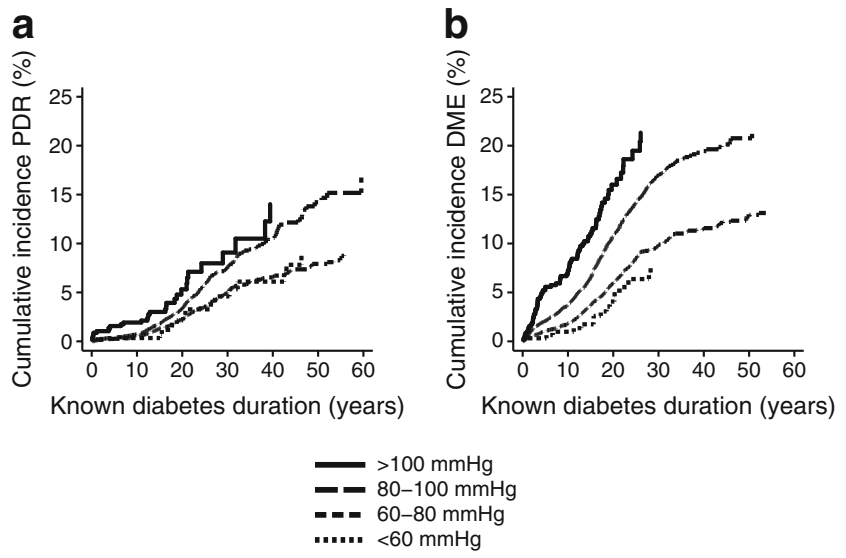

Fig. 3 Cumulative risk of developing (a) PDR and (b) DME, as a function of known diabetes duration, for patients stratified according to the weighted exposure to DBP ( $>100 \mathrm{mmHg}, n=314 ; 80-100 \mathrm{mmHg}$, $n=5958 ; 60-80 \mathrm{mmHg}, n=6187 ;<60 \mathrm{mmHg}, n=576$ )

of known diabetes duration. The stratification according to time of onset of diabetes showed that the cumulative incidence of the two sight-threatening complications decreased with later year of onset of diabetes when diabetes duration was $>10$ years $(p<0.03)$, and the stratification according to sex showed that the cumulative incidence of both PDR and DME was significantly higher for men than for women ( $p<0.004$ for all the studied diabetes durations; not shown).

The cumulative incidence of both PDR and DME was lowest in patients with $\mathrm{wHbA}_{1 \mathrm{c}}$ in the interval $40-70 \mathrm{mmol} /$ mol (5.8-11.3\%) (Fig. 2). The cumulative incidence of both complications at diabetes durations of 20,30 and 40 years increased significantly with increasing $\mathrm{wHbA}_{1 \mathrm{c}}(p<0.04$ for all comparisons), but the cumulative incidence of PDR was also significantly higher in patients with lower $\mathrm{wHbA}_{1 \mathrm{c}}$ values $(p<0.013)$. Further stratification of $\mathrm{wHbA}_{1 \mathrm{c}}$ in intervals of $10 \mathrm{mmol} / \mathrm{mol}$ showed that $\mathrm{wHbA}_{1 \mathrm{c}}$ values between 30 and $40 \mathrm{mmol} / \mathrm{mol}(4.9 \%$ and $5.8 \%)$ were accompanied with the lowest cumulative incidence of both PDR and DME. The
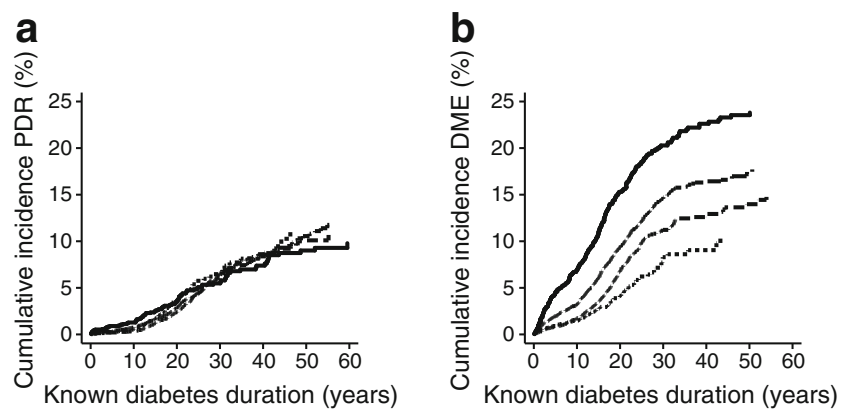

$$
\begin{array}{ll} 
& >160 \mathrm{mmHg} \\
\mathbf{Z} & 140-160 \mathrm{mmHg} \\
\mathbf{E -} & 120-140 \mathrm{mmHg} \\
\ldots . . . & <120 \mathrm{mmHg}
\end{array}
$$

Fig. 4 Cumulative risk of developing (a) PDR and (b) DME, as a function of known diabetes duration, for patients stratified according to the weighted exposure to SBP ( $>160 \mathrm{mmHg}, n=2010,140-160 \mathrm{mmHg}$, $n=5162 ; 120-140 \mathrm{mmHg}, n=3966 ;<120 \mathrm{mmHg}, n=1897$ )
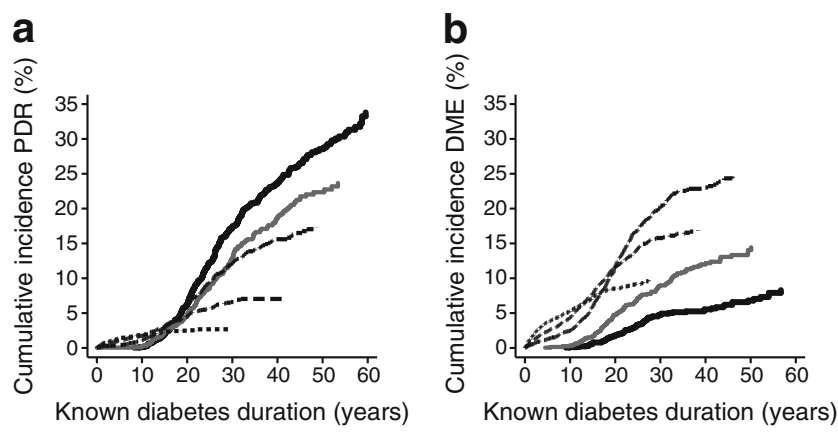

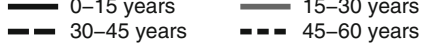

Fig. 5 Cumulative risk of developing (a) PDR and (b) DME, as a function of known diabetes duration, for patients stratified according to the known age of onset of diabetes $(0-15$ years, $n=1995 ; 15-30$ years, $n=2247 ; 30-45$ years, $n=3299 ; 45-60$ years, $n=5411 ;>60$ years, $n=$ 4554)

cumulative incidence of PDR and DME also increased with increasing $\mathrm{CV}$ of $\mathrm{HbA}_{1 \mathrm{c}}(p<0.0001$ for all comparisons; not shown).

Figure 3 shows that the cumulative incidence of both PDR and DME increased with increasing DBP $(p<0.0001$ for all diabetes durations in all four strata). For diabetes durations $>10$ years the cumulative incidence of PDR was not significantly different among the two strata with the lowest and among the two strata with the highest DBP ( $p>0.11$ for all pairwise comparisons), suggesting a threshold value for the risk induced by the DBP of about $80 \mathrm{mmHg}$.

For diabetes durations $>10$ years the cumulative incidence of PDR was independent of the SBP ( $p>0.08$ for all comparisons) (Fig. 4). However, the cumulative incidence of DME increased significantly with increasing $\operatorname{SBP}(p<0.0001$ for all comparisons), reaching $23 \%$ for SBP $>160 \mathrm{mmHg}$.

The cumulative incidence of PDR was maximal for patients with the earliest onset of diabetes and decreased with increasing age of onset $(p<0.0001$ for diabetes durations $\geq 20$ years) (Fig. 5). However, the cumulative incidence of DME was maximal for a known onset of diabetes between 30 and 45 years of age and decreased significantly for both lower and higher ages of onset $(p<0.0001$ for diabetes durations $\geq 20$ years). For both complications, but especially for DME, the initial rise in the cumulative incidence curves is seen to be increasingly left-displaced with increasing age of onset of diabetes. A further stratification of the dataset narrowed the age of onset with maximum risk of DME being between 30 and 35 years of age (not shown).

\section{Discussion}

The purpose of the study was to investigate whether systemic risk factors may contribute differently to the development of 
either of the two sight-threatening complications PDR and diabetic maculopathy with clinically significant DME. The omission of retinopathy grade as a risk factor in the analysis [18] prevented dependencies because the cumulative exposure to this variable would be identical to the treatment endpoint.

In previous studies the inclusion of diabetes type as a risk factor $[12,19]$ has been hampered by changes in the definition of this variable over time [9]. In the absence of measurements of serum C-peptide and autoantibodies, diabetes type is defined on the basis of a set of variables such as age of onset of diabetes and mode and time of onset of treatment [20]. This might potentially have masked effects of interactions among these variables. In addition, previous cohort studies have not fully considered that correlations between risk factors and disease progression may show bimodal effects and that the risk of reaching an endpoint should correct for selection because of death of the population over time.

The present study addresses these challenges by investigating the role of individual systemic risk factors for developing PDR or DME using survival analysis with death as a competing risk. The finding of a lower risk of developing sight-threatening retinopathy with later year of onset of diabetes may be a result of improvements in general diabetes care, whereas the lack of significant change in the duration of diabetes at the time of first treatment indicates that the natural history of diabetic retinopathy and the practice patterns for diabetic individuals referred to the eye department have not changed appreciably during the period of data sampling [21]. At the design of the study, it was planned to include the use of insulin as a covariate [22], but the exact time of onset of insulin medication was unknown in a large number of patients with late-onset diabetes. Therefore, the effect of this factor could not be evaluated in the survival analysis. In addition, the calculation of the time-to-event was hampered by the fact that the true onset of diabetes in older patients might have been several years earlier than the reported onset of the disease [23]. This may explain the observed leftdisplacement of the cumulative incidence curves for increasing age of onset of diabetes. However, a repeated analysis, after the diabetes duration in those categorised as having type 2 diabetes had been tentatively increased and the age of onset of diabetes decreased by 7 years [24], yielded similar results, which argues that an overestimation of the age of onset of diabetes in these patients had not influenced the conclusions. The asymptotic maxima of the cumulative incidence curves reflected the proportion of patients in the studied population who would eventually develop a sight-threatening complication. Since the number of patients with uncomplicated diabetes who were screened by privately practising ophthalmologists was unknown, the proportion of those developing sightthreatening retinopathy in the diabetes population as a whole was lower but cannot be evaluated in detail.

The study extends previous findings that male sex is a risk factor for developing PDR [25] and sight-threatening retinopathy in general [12], by showing that male sex is also a risk factor for the development of DME. The background for this sex difference has not been clarified, but the observation may be a consequence of hormonal and psychosocial factors [26].

The study also confirmed that increasing $\mathrm{HbA}_{1 \mathrm{c}}$ concentrations above normal are associated with an increasing risk of progression of retinopathy resulting in both PDR and DME [22, 27-30]. In some recent studies $\mathrm{HbA}_{1 \mathrm{c}}$ has not been found to be a risk factor for the development of DME [31-33] or PDR [34, 35]. However, in these studies conclusions were based on single $\mathrm{HbA}_{1 \mathrm{c}}$ values obtained at the time of examination. These values did not reflect the metabolic regulation beyond the preceding 3 months, and possible opposite effects of low and high values were not considered by stratification of the data. This was considered in the present study, where the ${ }_{w H b A}$ c reflected metabolic regulation during the entire diabetes duration and was stratified to take into account the higher risk of $\mathrm{HbA}_{1 \mathrm{c}}$ values below normal. A similar bimodal relation has been shown for macrovascular complications, where both lower and higher than normal $\mathrm{HbA}_{1 \mathrm{c}}$ values increased mortality risk [36]. This may explain the lack of observation of patients with long diabetes durations among those with lower than normal $\mathrm{HbA}_{1 \mathrm{c}}$ in the present study. The finding has been attributed to a reverse causality, where low $\mathrm{HbA}_{1 \mathrm{c}}$ values are considered to be a consequence of other systemic disease, but it cannot be excluded that actively attempted tight metabolic control had increased the risk of progression of retinopathy, as observed in the DCCT [30]. The observed $\mathrm{wHbA}_{1 \mathrm{c}}$ values below $40 \mathrm{mmol} / \mathrm{mol}(5.8 \%)$ represented 8553 observations from 572 patients and had a mean of $35.5 \mathrm{mmol} / \mathrm{mol}(5.4 \%)$ with a $95 \%$ CI of 35.0 , $35.9 \mathrm{mmol} / \mathrm{mol}(5.36 \%, 5.45 \%)$. This amount of data underlines the empirical support for the conclusions, but the fact that the increased risk induced by lower than normal $\mathrm{HbA}_{1 \mathrm{c}}$ values contributed significantly to the development of PDR but not DME requires further investigation. This supports the existence of a different risk pattern for the two complications.

The increasing risk of developing both PDR and DME with increasing $\mathrm{CV}$ of $\mathrm{HbA}_{1 \mathrm{c}}$ confirms previous studies, both in extraocular organs [37] and in the eye [38], and underlines that the development of diabetic late complications is accelerated by an unstable metabolic environment [39].

The findings also confirm evidence that the risk of progression of retinopathy to PDR increases with increasing DBP but is unaffected by SBP in individuals with early-onset diabetes [40] and in those with type 1 diabetes [30], in whom PDR is the most frequent sight-threatening complication. In addition, the study confirms observations that an increase in both the DBP and the SBP can increase the risk of progression of diabetic retinopathy in individuals with late-onset diabetes and in those with type 2 diabetes, in whom DME is the most frequent sight-threatening complication [29, 41, 42]. This concurs with the notion that DME is due to hyperpermeability 
facilitated by increased hydrostatic pressure in the retinal capillaries [38, 43-45] which may be related to hyperfiltration in the kidney [46]. The association between the cumulative exposure to the $\mathrm{BP}$ and the development of sight-threatening diabetic retinopathy argues for the use of BP-lowering medication to prevent progression of retinopathy [29]. The fact that several intervention studies have failed to show such an effect may be due to the slow progression of the disease [47, 48]; therefore, future intervention studies should address the longterm cumulated exposure to the BP.

The observed latency between onset of diabetes during childhood and the development of PDR may explain previous observations of a lower 10 year incidence of PDR in people with onset of diabetes before the age of 10 years compared with onset between 10 and 29 years of age [49]. The increased risk of developing PDR with earlier onset of diabetes is similar to the risk of developing PDR after treatment for DME [10]. The finding suggests that the risk of developing PDR is enhanced by metabolic disturbances in the growing organism, potentially related to the activity of growth factors [50]. By contrast, the risk of developing DME was highest in patients with an age of onset of diabetes between 30 and 45 years and decreased with both increasing and decreasing age of onset. A further stratification of the dataset narrowed the age of onset with maximum risk being between 30 and 35 years of age (not shown). Age of onset of diabetes at about 30 years has traditionally been used to define diabetes type [9] and was the criterion for the dichotomous allocation of individuals to groups with early- and late-onset diabetes in the Wisconsin Epidemiologic Study of Diabetic Retinopathy [41, 42]. The present findings argue that risk models for the development of sight-threatening retinopathy should include the age of onset of diabetes as a continuous variable where the risks of developing PDR and DME are calculated separately.

The present study used survival analysis and a large dataset with a long follow-up time from a well-defined population to study the effect of a number of systemic risk factors for the development of sight-threatening retinopathy. The results explain the general clinical experience that the incidence of PDR in type 1 diabetic patients in whom the age of onset of diabetes is by definition early in life increases from early adulthood [25]. The increase in the number of people with type 2 diabetes, among whom an increasing number experience onset of diabetes before the age of 30 years, has therefore come to contribute significantly to the current incidence of PDR [1]. Similarly, the increasing incidence of DME reflects the increase in the incidence of type 2 diabetes, which usually manifests in adulthood [1]. Finally, the results are concordant with the experience that people with type 2 diabetes with onset of diabetes late in life have a low risk of developing sightthreatening diabetic retinopathy $[51,52]$.

Altogether, the study showed that systemic risk factors such as metabolic regulation, arterial BP and the age of onset of diabetes contribute differently to the development of the two late complications PDR and DME. This suggests that the overall risk of developing sight-threatening diabetic retinopathy should be assessed by adding the risks of developing each of the two complications separately. Knowledge about systemic risk factors should be integrated into risk models that include retinopathy grade, that consider interactions among risk factors and that are applicable at all stages in disease development. The risk calculation might benefit from replacing diabetes type with the individual parameters used to define this variable.

Acknowledgements The Department of Biostatistics, Aarhus University, helped to design and interpret the statistical analyses. The skilful assistance of nurse photographers H. Hedegaard and T. Bjerre is gratefully acknowledged.

Data availability According to restrictions of the Danish Data Protection Agency, patient data are not publicly available.

Funding This research received no specific grant from any funding agency in the public, commercial or not-for-profit sectors.

Authors' relationships and activities The author declares that there are no relationships or activities that might bias, or be perceived to bias, this work.

Contribution statement The author conceived the study, collected and analysed the data and wrote the manuscript.

\section{References}

1. Yau JWY, Rogers SL, Kawasaki R et al (2012) Global prevalence and major risk factors of diabetic retinopathy. Diabetes Care 35(3): 556-564. https://doi.org/10.2337/dc11-1909

2. Bek T (2009) Inner retinal ischaemia: current understanding and needs for further investigations. Acta Ophthalmol 87(4):362-367. https://doi.org/10.1111/j.1755-3768.2008.01429.x

3. Bek T (2013) Regional morphology and pathophysiology of retinal vascular disease. Prog Retin Eye Res 36:247-259. https://doi.org/ 10.1016/j.preteyeres.2013.07.002

4. Norton E, Davis MD, Fine SL et al (1968) The Airlie House classification of diabetic retinopathy. Symposium on the treatment of diabetic retinopathy. In: Goldberg MF, Fine SL (eds) US Department of Health, Education and Welfare pp 7-22

5. Wilkinson CP, Ferris FL 3rd, Klein RE et al (2003) Proposed international clinical diabetic retinopathy and diabetic macular edema disease severity scales. Ophthalmology 110(9):1677-1682. https:// doi.org/10.1016/S0161-6420(03)00475-5

6. Grauslund J, Andersen N, Andresen J et al (2018) Evidence-based Danish guidelines for screening of diabetic retinopathy. Acta Ophthalmol 96(8):763-769. https://doi.org/10.1111/aos.13936

7. Varma R, Bressler NM, Doan QV et al (2014) Prevalence and risk factors for diabetic macular edema in the United States. JAMA Ophthalmol 132(11):1334-1340. https://doi.org/10.1001/ jamaophthalmol.2014.2854

8. Bek T, Jørgensen CM (2016) The systemic blood pressure and oxygen saturation in retinal arterioles predict the effect of intravitreal anti-VEGF treatment on diabetic maculopathy. Invest 
Ophthalmol Vis Sci 57(13):5429-5434. https://doi.org/10.1167/ iovs. 16-20305

9. Zaccardi F, Webb DR, Yates T et al (2016) Pathophysiology of type 1 and type 2 diabetes mellitus: a 90 -year perspective. Postgrad Med J 92(1084):63-69. https://doi.org/10.1136/ postgradmedj-2015-133281

10. Bek T (2020) Incidence and risk factors for developing proliferative diabetic retinopathy after photocoagulation for diabetic maculopathy. Curr Eye Res 45(8):986-991. https://doi.org/10. 1080/02713683.2020.1712729

11. Bek T (2005) Diabetic retinopathy: a review of the Aarhus approach to studies on epidemiology, computerised grading, and the pathophysiology of the disease. Horm Metab Res 37(Suppl 1): 35-38

12. Mehlsen J, Erlandsen M, Poulsen PL et al (2011) Identification of independent risk factors for the development of diabetic retinopathy requiring treatment. Acta Ophthalmol 89(6):515-521. https://doi. org/10.1111/j.1755-3768.2009.01742.x

13. Bek T (2018) Arterial oxygen saturation in neovascularizations in proliferative diabetic retinopathy. Retina 38(12):2301-2308. https://doi.org/10.1097/IAE.0000000000001870

14. Bek T, Erlandsen M (2006) Visual prognosis after panretinal photocoagulation for proliferative diabetic retinopathy. Acta Ophthalmol 84(1):16-20

15. Early Treatment Diabetic Retinopathy Study Research Group (1985) Photocoagulation for diabetic macular edema. ETDRS report number 1. Arch Ophthalmol 103(12):1796-1806

16. Bek T, Møller F, Klausen B (2000) Short term visual prognosis after retinal laser photocoagulation for diabetic maculopathy. Acta Ophthalmol 78(5):539-542. https://doi.org/10.1034/j.1600-0420. 2000.078005539.x

17. Klein JP, Logan B, Harhoff $M$ et al (2007) Analyzing survival curves at a fixed point in time. Stat Med 26(24):4505-4519. https://doi.org/10.1002/sim.2864

18. Leese GP, Stratton IM, Land M et al (2015) Progression of diabetes retinal status within community screening programs and potential implications for screening intervals. Diabetes Care 38(3):488-494. https://doi.org/10.2337/dc14-1778

19. Lund SH, Aspelund T, Kirby P (2016) Individualised risk assessment for diabetic retinopathy and optimisation of screening intervals: a scientific approach to reducing healthcare costs. Br J Ophthalmol 100(5):683-687. https://doi.org/10.1136/ bjophthalmol-2015-307341

20. Hörber S, Achenbach P, Schleicher E et al (2020) Harmonization of immunoassays for biomarkers in diabetes mellitus. Biotechnol Adv 39:107359. https://doi.org/10.1016/j.biotechadv.2019.02.015

21. Sabanayagam C, Yip W, Ting DS et al (2016) Ten emerging trends in the epidemiology of diabetic retinopathy. Ophthalmic Epidemiol 23(4):209-222. https://doi.org/10.1080/09286586.2016.1193618

22. Klein R, Moss SE, Klein BEK et al (1989) The Wisconsin Epidemiologic Study of Diabetic Retinopathy. XI. The incidence of macular edema. Ophthalmology 96:1501-1510. https://doi.org/ 10.1016/S0161-6420(89)32699-6

23. Hove MN, Kristensen JK, Lauritzen T et al (2004) The prevalence of retinopathy in an unselected population of type 2 diabetes patients from Aarhus County, Denmark. Acta Ophthalmol 82(4): 443-448. https://doi.org/10.1111/j.1600-0420.2004.00270.x

24. Harris MI, Eastman RC (2000) Early detection of undiagnosed diabetes mellitus: a US perspective. Diabetes Metab Res Rev 16: 230-236. https://doi.org/10.1002/1520-7560(2000)9999:9999<:: AID-DMRR122>3.0.CO;2-W

25. Klein R, Klein BEK, Moss SE et al (1998) The Wisconsin Epidemiologic Study of Diabetic Retinopathy: XVII. The 14-year incidence and progression of diabetic retinopathy and associated risk factors in type 1 diabetes. Ophthalmology 105(10):18011815. https://doi.org/10.1016/S0161-6420(98)91020-X
26. Kautzky-Willer A, Harreiter J, Pacini G (2016) Sex and gender differences in risk, pathophysiology and complications of type 2 diabetes mellitus. Endocr Rev 37(3):278-316. https://doi.org/10. 1210/er.2015-1137

27. DCCT Research Group (1993) The effect of intensive diabetes treatment on the development and progression of long term complication in insulin-dependent diabetes mellitus. N Engl J Med 329: 977-986. https://doi.org/10.1056/NEJM199309303291401

28. Davis MD, Fisher MR, Gangnon RE et al (1998) Risk factors for high-risk proliferative diabetic retinopathy and severe visual loss: Early Treatment Diabetic Retinopathy Study report \#18. Invest Ophthalmol Vis Sci 39(2):233-252

29. Stratton IM, Kohner EM, Aldington SJ et al (2001) UKPDS 50: risk factors for incidence and progression of retinopathy in type II diabetes over 6 years from diagnosis. Diabetologia 44:156-163. https:// doi.org/10.1007/s001250051594

30. Hainsworth DP, Bebu I, Aiello LP et al (2019) Risk factors for retinopathy in type 1 diabetes: the DCCT/EDIC study. Diabetes Care 42(5):875-882. https://doi.org/10.2337/dc18-2308

31. Acan D, Karahan E, Kocak N, Kaynak S (2018) Evaluation of systemic risk factors in different optical coherence tomographic patterns of diabetic macular edema. Int J Ophthalmol 11(7):12041209

32. Peng Y-J, Tsai M-J (2018) Impact of metabolic control on macular thickness in diabetic macular oedema. Diab Vasc Res 15(2):165168. https://doi.org/10.1177/1479164117746023

33. Bansal AS, Khurana RN, Wieland MR, Wang P-W, Van Everen SA, Tuomi L (2015) Influence of glycosylated hemoglobin on the efficacy of ranibizumab for diabetic macular edema. Ophthalmology 122:1573-1579. https://doi.org/10.1016/j.ophtha. 2015.04.029

34. Nittala MG, Keane PA, Zhang K, Sadda SR (2014) Risk factors for proliferative diabetic retinopathy in a Latino American population. RETINA 34:1594-1599. https://doi.org/10.1097/IAE. 0000000000000117

35. Penman A, Hancock H, Papavasileiou E et al (2016) Risk factors for proliferative diabetic retinopathy in African Americans with type 2 diabetes. Ophthalmic Epidemiol 23(2):88-93. https://doi. org $/ 10.3109 / 09286586.2015 .1119287$

36. Li W, Katzmazyk PT, Horswell R et al (2016) $\mathrm{HbA}_{1 \mathrm{c}}$ and all-cause mortality risk among patients with type 2 diabetes. Int J Cardiol 202:490-496. https://doi.org/10.1016/j.ijcard.2015.09.070

37. Ceriello A, De Cosmo S, Rossi MC et al (2017) Variability in $\mathrm{HbA}_{1 \mathrm{c}}$, blood pressure, lipid parameters and serum uric acid, and risk of development of chronic kidney disease in type 2 diabetes. Diabetes Obes Metab 19(11):1570-1578. https://doi.org/10.1111/ dom. 12976

38. Takao T, Suka M, Yanagisawas H (2017) Predictive ability of visitto-visit variability in $\mathrm{HbA}_{1 \mathrm{c}}$ and systolic blood pressure for the development of microalbuminuria and retinopathy in people with type 1 diabetes. Diabetes Res Clin Pract 128:15-23. https://doi.org/ 10.1016/j.diabres.2017.03.027

39. Monnier L, Colette C, Dejager S et al (2016) Near normal $\mathrm{HbA}_{1 \mathrm{c}}$ with stable glucose homeostasis: the ultimate target/aim of diabetes therapy. Rev Endocr Metab Disord 17(1):91-101. https://doi.org/ 10.1007/s11154-016-9325-8

40. Klein R, Klein BEK, Moss SE et al (1984) The Wisconsin Epidemiologic Study of Diabetic Retinopathy. IX. Four-year incidence and progression of diabetic retinopathy when age at diagnosis is less than 30 years. Arch Ophthalmol 197:237-243

41. Klein R, Klein BEK, Moss SE et al (1984) The Wisconsin Epidemiologic Study of Diabetic Retinopathy. IX. Four-year incidence and progression of diabetic retinopathy when age at diagnosis is 30 or more years. Arch Ophthalmol 197:244-249

42. Kohner EM, Aldington SJ, Stratton IM et al (1998) United Kingdom UK Prospective Diabetes Study, 30. Diabetic retinopathy 
at diagnosis of non-insulin-dependent diabetes mellitus and associated risk factors. Arch Ophthalmol 116:297-303. https://doi.org/ 10.1001/archopht.116.3.297

43. Tilma KK, Bek T (2012) Topical treatment for 1 week with latanoprost but not diclofenac reduces the diameter of dilated retinal arterioles in patients with type 1 diabetes mellitus and mild retinopathy. Acta Ophthalmol 90(8):750-755. https://doi.org/10.1111/j. 1755-3768.2011.02185.x

44. Petersen L, Bek T (2016) The diameter response of retinal arterioles in diabetic maculopathy is reduced during hypoxia and is unaffected by the inhibition of cyclo-oxygenase and nitric oxide synthesis. Graefes Arch Clin Exp Ophthalmol 254(12):2339-2346. https:// doi.org/10.1007/s00417-016-3399-6

45. Bek T (2017) Diameter changes of retinal vessels in diabetic retinopathy. Curr Diab Rep 17(10):82. https://doi.org/10.1007/s11892017-0909-9

46. Hammes H-P, Welp R, Kempe H-P et al (2015) Risk factors for retinopathy and DME in type 2 diabetes - results from the German/ Austrian DPV database. PLoS One 10(7):e0132492. https://doi.org/ 10.1371/journal.pone.0132492

47. Chew EY, Davis MD, Danis RP et al (2014) The effects of medical management on the progression of diabetic retinopathy in persons with type 2 diabetes: the ACCORD eye study. Ophthalmology 121(12):2443-2451. https://doi.org/10.1016/j.ophtha.2014.07.019
48. Hata J, Arima H, Rothwell PM et al (2013) Effects of visit-to-visit variability in systolic blood pressure on macrovascular and microvascular complications in patients with type 2 diabetes mellitus. The ADVANCE trial. Circulation 128:1325-1334. https://doi.org/ 10.1161/CIRCULATIONAHA.113.002717

49. Klein R, Klein BEK, Moss SE et al (1994) The Wisconsin Epidemiologic Study of Diabetic Retinopathy. XIV. Ten-year incidence and progression of diabetic retinopathy. Arch Ophthalmol 112:1217-1228. https://doi.org/10.1001/archopht.1994. 01090210105023

50. Merimee TJ, Zapf J, Froelich ER (1983) Insulin-like growth factors. N Engl J Med 309:527-530. https://doi.org/10.1056/ NEJM198309013090904

51. Klein R, Davis MD, Moss SE et al (1985) The Wisconsin Epidemiologic Study of Diabetic Retinopathy. A comparison of retinopathy in younger and older onset diabetic persons. Adv Exp Med Biol 189:321-335

52. Agardh E, Tabakat-Khani P (2011) Adopting 3-year screening intervals for sight-threatening retinal vascular lesions in type 2 diabetic subjects without retinopathy. Diabetes Care 34(6):1318 1319. https://doi.org/10.2337/dc10-2308

Publisher's note Springer Nature remains neutral with regard to jurisdictional claims in published maps and institutional affiliations. 